\title{
Study Team Convenes on New TMS Report; AIME Offers New Oral Histories; TMS Participates in Congressional Briefing \\ themagazine
}

\section{member news}

Share the good news

about your professional

accomplishments!

Contact Kaitlin Calva,

JOM Magazine

Managing Editor,

at kcalva@tms.org.

Please note that only

news submitted by

current TMS members

will be considered.

\section{Study Team Looks at Next-Generation MGI Workforce}

Earlier this year, 11 of 16 team members met at TMS headquarters to begin work on a new study, Creating the Next-Generation Materials Genome Initiative (MGI)

Workforce, which is being conducted by TMS on behalf of the U.S. National Science Foundation. Led by David McDowell of the Georgia Institute of Technology, this team of subject matter experts will draw on the outputs of such meetings and workshops to provide detailed, actionable recommendations within the report. Workforce aims to address one of the four key goals of the 2014 MGI Strategic Plan: "creating a world-class materials-science and engineering workforce that is trained for careers in academia or industry." The MGI is
Creating the Next-Generation MGI

Pictured row 1, left to right: Mark D. Asta, Lawrence Berkley National Laboratory; George Rodriguez, ExxonMobil Chemical; Will Joost, Pratt \& Whitney; and Aaron Gilad Kusane, National Institute of Standards and Technology. Row 2, left to right: Matt Earnest, Virginia Polytechnic Institute and State University; Xin Sun, Oak

Ridge National Laboratory; Kevin Anderson, Brunswick Corporation; and Stefano Curtarolo, Duke University. Row 3, left to right: Raymundo Arroyave, Texas A\&M University; Cathy Tway, Johnson Matthey; and David McDowell, study team chair and Georgia Institute of Technology.

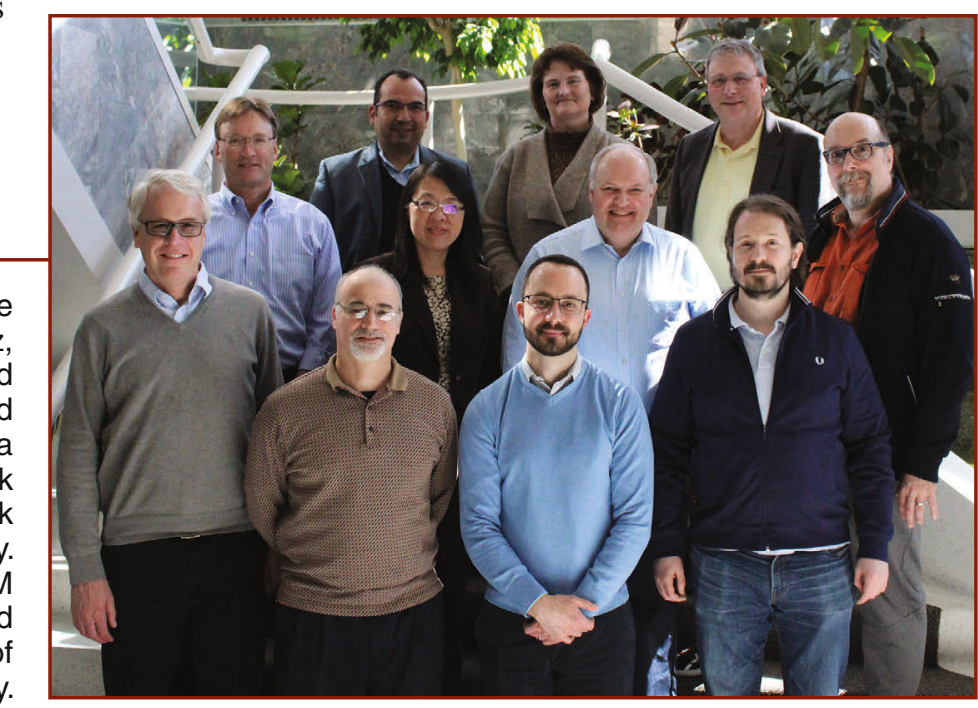

a multi-agency initiative from the U.S. government that is designed to support and accelerate the design, development, and deployment of advanced materials. The final report will address the current state of the academic curriculum and training approaches of the U.S. workforce to accomplish MGI goals, identify the key MGI skill requirements and needs for individuals entering the workforce, and outline curricula development and training guidelines to improve readiness of current students and the existing professional workforce. Learn more and sign up for updates at www.tms.org/MGIWorkforce.

\section{Brush Up on Your Materials History with AIME}

The American Institute of Mining, Metallurgical, and Petroleum Engineers (AIME), TMS's parent organization, has released a series of new video interviews as a part of its Oral History project. The project aims to "honor the legacy and traditions of AIME," one of the four facets of the Institute's mission, by preserving and promoting achievements in the fields and sharing prominent member stories with future generations. From April through August 2019, a total of 11 new audio and video captures from experienced members in industry, academia, and government have been added to the existing collection of histories, which features interviews from eight TMS members:

- Ray Smith, President, Michigan Technological University (retired)

- Harry Paxton, U.S. Steel Professor Emeritus, Department of Materials Science, Carnegie Mellon University

- Patrick Taylor, Director, Kroll Institute for Extractive Metallurgy, 
Colorado School of Mines

- Peter Hayes, Professor of Metallurgical Engineering, University of Queensland

- Authur Pelton, Emeritus Professor, Department of Chemical Engineering, and Co-Directeur, Centre de Recherche en Calcul Thermochimique, École Polytechnique, Montréal

- Chris Bale, Adjunct Professor, Department of Chemical Engineering, and Co-Directeur, Centre de Recherche en Calcul Thermochimique, École Polytechnique, Montréal

- Sig Hecker, Director, Los Alamos
National Laboratory (retired)

- David Matlock, Professor Emertius, Colorado School of Mines

Visit the AIME Oral Histories web page at aimehq.org/programs/archives to learn the story of your profession in the words of those who have lived it. Additional histories are still under development and in production by AIME, with several new interviews scheduled for release in September 2019. Check the AIME Oral Histories page regularly for announcements when new TMS member interviews are available, or to submit a candidate for AIME's Oral History capture.

\section{TMS and CSM Discuss Collaboration}

On Thursday, May 9, TMS hosted Zhao Pei, Emeritus Secretary General of the Chinese Society for Metals (CSM), at TMS headquarters in Pittsburgh, Pennsylvania. During the course of the day, David DeYoung, 2017 TMS President, James J. Robinson, TMS Executive Director, and TMS senior staff acquainted Zhao with the Society's strategic goals and key initiatives. This included a review of past and current collaborations with CSM, such as the Energy Materials conference, co-located with the TMS 2017 Annual Meeting \& Exhibition, and the Computational Design and Simulation of Materials conference, co-located with the TMS 2018 Annual Meeting \& Exhibition.

The discussion then turned to the potential of future collaborations, with participation by Thomas Battle, 2019 TMS Vice President, and Xingbo Liu, a TMS volunteer from West Virginia University who has helped facilitate joint initiatives between the two societies in the past, such as establishing the Energy Materials conference and leading the conference organization on behalf of TMS.

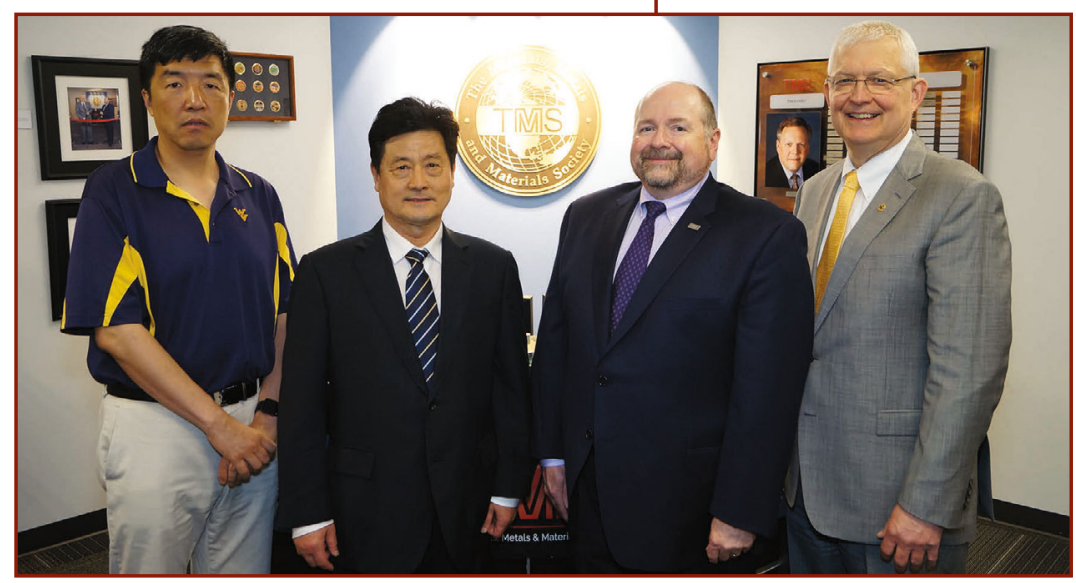

Pictured from left to right: Xingbo Lui, West Virginia University; Zhao Pei, Emeritus Secretary General, Chinese Society for Metals; James Robinson, TMS Executive Director; and David DeYoung, 2017 TMS President.

\section{TMS Reviews Revolutionary Technology at Congressional Briefing}

More than 80 Congressional staff members and others engaged with public policy development gathered on June 6 for a high-level overview of a potentially disruptive technology at a Congressional Briefing sponsored by TMS and the United Engineering Foundation, and hosted by the House Manufacturing Caucus.

The topic was metamorphic manufacturing, a new technology that forges metal objects to precise specifications through a combination of robotic systems, intelligent machines, sensors, and integrated computational learning. The need to produce a die is completely eliminated, while the incremental deformation approach minimizes waste and optimizes part performance and properties. Metamorphic manufacturing is particularly wellsuited for the production of highly specialized parts and, compared with other technologies, can potentially produce these parts cheaper, faster, at a higher quality, 


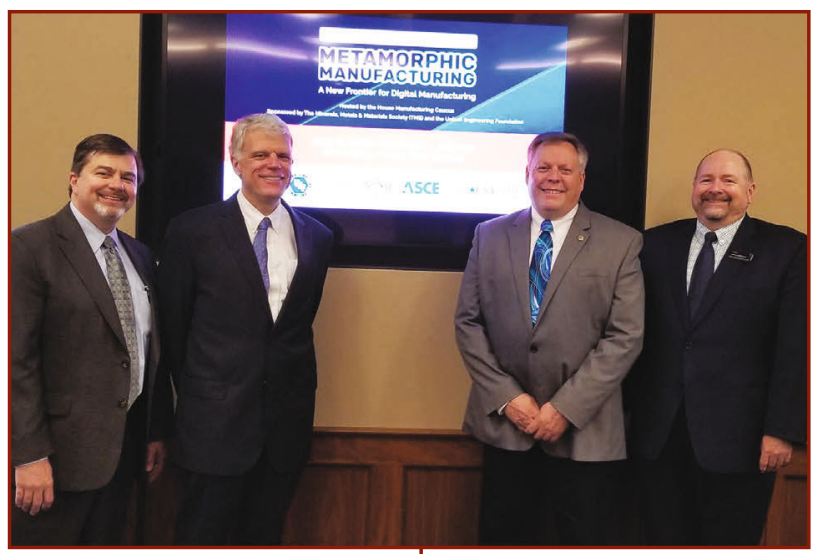

(Left to Right) George

Spanos, TMS Director of New Initiatives, Science, and Engineering, and Glenn Daehn, TMS Metamorphic Manufacturing study team lead, pause in their preparations for the Congressional Briefing on June 6 with James Foley, 2019 TMS President, and James J. Robinson, TMS Executive Director. and with a lower carbon output.

The technology was explored in-depth in the recently released TMS technical report, Metamorphic Manufacturing: Shaping the Future of

On-Demand Components

Glenn Daehn, the study team lead and Fontana Professor of Metallurgical Engineering at The Ohio State University, was the featured speaker at the briefing. He opened his talk with a history lesson, tracing how the implementation of key process innovations gave rise to the great manufacturing hubs of the United States, such as the automotive industry in Detroit. Metamorphic manufacturing, he noted, offers that same potential. "We need mindful policies to put metamorphic manufacturing into production," he said. The workforce implications of this investment, Daehn maintained, would be significant: "This new process will teach new skills and create a culture of doing."

The briefing concluded with a question and answer session moderated by George Spanos, TMS Director of New Initiatives, Science, and Engineering, with Daehn and Tony Schmitz, University of North Carolina at Charlotte and study team member, providing responses.

To download TMS's Metamorphic Manufacturing study, visit www.tms.org /MetamorphicManufacturing. A recording of the Congressional Briefing, including the question and answer session, can be accessed at housemanufacturingcaucusreed.house.gov/events/events-of-the-116thcongress- 0 .

The Congressional Briefing on Metamorphic Manufacturing is part of an advanced manufacturing briefing series supported by the United Engineering Foundation. The following organizations comprise the United Engineering Foundation: The American Institute of Mining, Metallurgical, and Petroleum Engineers (AIME), the American Society of Mechanical Engineers (ASME), the American Society of Civil Engineers (ASCE), IEEE USA, and the American Institute of Chemical Engineers (AIChE).

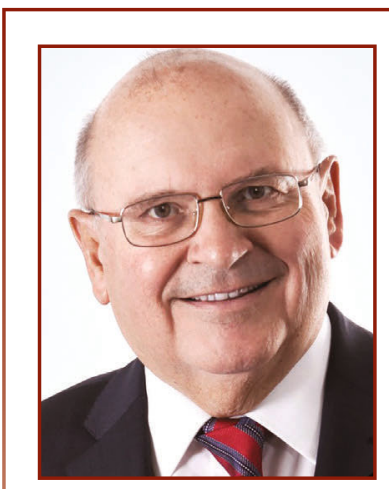

Alois Franke

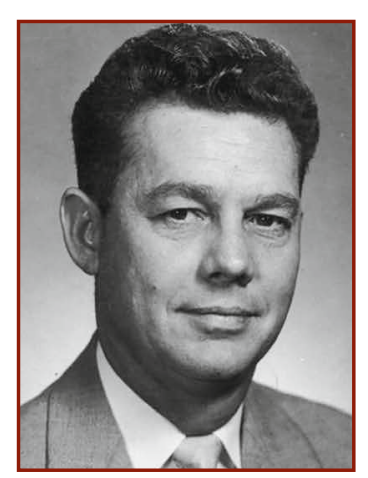

Richard E. Cole

\section{In Memoriam: Alois J. Franke \& Richard E. Cole}

TMS extends its condolences to the family, friends, and colleagues of the following members:

Alois J. Franke passed away in April 2019 at the age of 78 . Franke received his B.S. in physics, his M.S. in materials science, and his Ph.D. from Saarbrucken University in Germany. In 1993, Franke purchased the raw materials processing with specialty alloys, semi-finished products, and Soderberg paste businesses from German aluminum smelter Alusuisse to create Aluminium Rheinfelden. He served for many years as the company's managing director and chair of the board. Franke was a TMS member since 1980.

Richard E. Cole passed away at the age of 100 on March 6, 2019. Following his discharge from the U.S. Navy during WWII, Cole completed his bachelor's degree at the Missouri School of Mines (now Missouri University of Science \& Technology) and received his master's degree from the Massachusetts Institute of Technology. He then began working at Reynolds Metals as an engineer intern, rising through the company over the years before retiring in 1980 as vice president, member of the board of directors, and head of the Primary Metals Division. Cole was a TMS member since 1965. 